\title{
Applicability of Two Mixed Dentition Analysis in Children of Jangam Community of Belgaum City
}

\author{
Santosh M Sholapurmath, Deepa B Benni, Praveen Mandroli
}

\begin{abstract}
Background and objective: Many cases of malocclusion originate during the mixed dentition period. Moyers tables and Tanaka and J ohnston space analysis are the most commonly used mixed dentition space analysis. Based on the reported racial and sex differences in tooth sizes, the purpose of this study was to evaluate applicability of the Moyers, Tanaka and Johnston and method of prediction in a Belgaum population and develop a new prediction method for this specific population, if necessary.
\end{abstract}

Materials and methods: The study was conducted on sample of 140 children within the age group of 13 to 16 years old belonging to Jangam community, who had fully erupted mandibular permanent incisors and maxillary and mandibular canines and premolars. Mesiodistal crown widths of permanent teeth were measured using a digital calliper of resolution of $0.01 \mathrm{~mm}$. The odontometric values obtained were then subjected to statistical analysis (Student unpaired t-test).

Results: Gender discrepancy was seen in the study with male showing significantly greater maxillary canine-premolar segment. There is statistical significant difference in tooth dimension between the actual and predicted value at the 50th and 75th percentile of the Moyers probability tables for males and females in both the arches. There were significant differences between the actual measurements and measurements derived from the Tanaka and J ohnston equation.

Conclusion: The Moyers probability tables and Tanaka and J ohnston prediction method significantly underestimate canine and premolar mesiodistal width of J angam population, Indian origin.

Keywords: Mixed dentition, Moyers prediction table, Tanaka and J ohnston prediction method.

How to cite this article: Sholapurmath SM, Benni DB, Mandroli $P$. Applicability of Two Mixed Dentition Analysis in Children of J angam Community of Belgaum City. World J Dent 2012;3(4):324-329.

\section{Source of support: Nil}

\section{Conflict of interest: None declared}

\section{INTRODUCTION}

$M$ any cases of malocclusion originate during the mixed dentition period. During this critical period, the orthodontist or pediatric dentist is often asked to provide an accurate diagnosis of any developing malocclusions.

$M$ ixed dentition space analysis forms an essential part of diagnostic procedures. These analysis help to assess the amount of space required for the alignment of unerupted permanent teeth in a dental arch. Inappropriate and invalid mixed dentition space analysis results could lead to extraction decisions that negatively alter a patient's soft tissue facial profile. An accurate mixed dentition space analysis is one of the important criteria. Tooth size prediction of the unerupted permanent canines, first and second premolars forms part of the critical aspects of the mixed dentition space analysis.

Early treatment is becoming increasingly popular in the orthodontic circles and it is imperative that the mixed dentition space analysis is accurately done before such orthodontic treatment is offered. ${ }^{1,2}$ In planning the most expeditious management of such cases, it is imperative that any deficit of arch space be predicted in advance and the indicated procedures instituted early. ${ }^{2,3}$ Prominent among the conditions requiring early attention are those in which there is disparity between the amount of the dental arch space and the amount of tooth material, which should be accommodated in determining whether the treatment plan may involve serial extraction, guidance of eruption, space maintenance, space regaining or just periodic observation of the patients. ${ }^{1,4-6}$

Mixed dentition analysis using Moyers tables and Tanaka and Johnston have several advantages. No radiographs are required, tables can be used for both the maxillary and mandibular arch estimations, and there is fairly good accuracy despite a tendency to overestimate the size of unerupted teeth. ${ }^{2}$ The development of these two methods, however, was based on data derived from a population of Northern European descent. Therefore, the accuracy of these prediction methods may be in question when applied to a population of different ethnic origin. ${ }^{7,8}$ The purpose of this study was to:

1. Examine the applicability of the Tanaka and J ohnston and Moyers method of prediction in a Belgaum population.

2. Develop a new prediction method for this specific population, if it proved to be necessary.

\section{MATERIALS AND METHODS}

\section{Sample Selection}

Dental study casts of 70 males and 70 females subjects aged between 13 and 16 years old bel onging to J angam population 
were selected for this study. J angam population has a rich cultural heritage and racial mixing is limited in this population due to strong family bonds. The casts were made from dental impressions of children belonging to Jangam population in various schools of B el gaum city, after approval was obtained from their parents and teachers.

The criteria for sample selection were the following:

1. The mandibular permanent incisors, the mandibular and maxillary permanent canines, and the mandibular and maxillary premolars were fully erupted.

2. No congenital craniofacial anomalies or previous history of orthodontic treatment.

3. Intact dentition with no proximal caries, restorations or age-related attrition.

4. Parents of the subject should belong to the Jangam community.

5. The dental impressions and study casts were of high quality and free of distortion.

The mesiodistal dimensions of the mandibular permanent central and lateral incisors, the maxillary and mandibular permanent canines, and the first and second premolars were measured using a Digimatic Caliper (Mitutoyo) with a resolution of $0.01 \mathrm{~mm}$. The values obtained from the right and left canine-premolar segments in each arch were averaged, so that there would be one value for the mandibular canine-premolar segment and one value for the maxillary canine-premolar segment for each value of the combined mandibular incisors. For measurement reliability, teeth were measured manually and independently by two investi gators. The two measurements obtained were compared and if they varied by $0.2 \mathrm{~mm}$ or less, the values were averaged. In instances where the measurements varied by more than $0.2 \mathrm{~mm}$, the teeth were remeasured and the nearest three measurements were averaged.

A standardized method proposed by M oorrees and R eed ${ }^{9}$ was used to measure the mesiodistal crown widths. The greatest mesiodistal crown width of each tooth was measured between its contact points, with the sliding caliper placed parallel to the occlusal and vestibular surfaces. This method was reported to be highly repeatable and accurate for measuring mesiodistal crown widths by Doris et al. ${ }^{10}$

\section{RESULTS}

Descriptive statistics, including the mean, standard deviation, standard error and coefficient of variation for both male and female are presented in Table 1. A Student unpaired t-test was cal culated to compare tooth dimensions between male and female subjects. A gender discrepancy was seen in the study with male showing significantly greater maxillary canine-premolar segment.

Table 2 shows the regression parameters for prediction of summations of mesiodistal widths of canine and premolars (dependent variable) using the mesiodistal widths of mandibular incisors (independent variables). The coefficient correlation ( $r$ ) was calculated to find the correlation between the sums of canine and premolars in both arches with that of the sum of mandibular incisors. The correlation coefficient ranged from 0.36 to 0.68 with

Table 1: Descriptive statistics including mean, standard deviation and CV for summations of mesiodistal widths of mandibular incisors, maxillary and mandibular canine and premolar segments

\begin{tabular}{|c|c|c|c|c|c|c|c|}
\hline Tooth group & Sex & Mean & Standard deviation & Standard error & $\mathrm{CV}$ & t-value & $p$-value \\
\hline Mandibular incisors & $\begin{array}{l}M \\
F\end{array}$ & $\begin{array}{l}23.49 \\
23.46\end{array}$ & $\begin{array}{l}1.48 \\
1.56\end{array}$ & $\begin{array}{l}0.18 \\
0.19\end{array}$ & $\begin{array}{l}6.30 \\
6.65\end{array}$ & 0.1112 & 0.9116 \\
\hline $\begin{array}{l}\text { Maxillary canine } \\
\text { Premolar segment }\end{array}$ & $\begin{array}{l}M \\
F\end{array}$ & $\begin{array}{l}24.31 \\
23.77\end{array}$ & $\begin{array}{l}1.34 \\
1.73\end{array}$ & $\begin{array}{l}0.16 \\
0.21\end{array}$ & $\begin{array}{l}5.50 \\
7.28\end{array}$ & 2.0543 & $0.0418 *$ \\
\hline $\begin{array}{l}\text { Mandibular canine } \\
\text { Premolar segment }\end{array}$ & $\begin{array}{l}M \\
F\end{array}$ & $\begin{array}{l}23.65 \\
23.08\end{array}$ & $\begin{array}{l}1.91 \\
1.65\end{array}$ & $\begin{array}{l}0.23 \\
0.20\end{array}$ & $\begin{array}{l}8.07 \\
7.15\end{array}$ & 1.8949 & 0.0602 \\
\hline
\end{tabular}

*Significant at $p<0.05 ; C V$ : Coefficient of variation

Table 2: Regression parameters for prediction of summations of mesiodistal widths of canine and premolars (dependent variable) using the mesiodistal widths of mandibular incisors (independent variables)

\begin{tabular}{llllllllll}
\hline $\begin{array}{l}\text { Dependent } \\
\text { variable }\end{array}$ & Variables & $\begin{array}{l}\text { Correlation } \\
\text { coefficient }\end{array}$ & $\begin{array}{l}\text { Coefficient } \\
\text { of } \\
\text { determination }\end{array}$ & Constant & $\begin{array}{l}\text { Regression } \\
\text { coefficient }\end{array}$ & $\begin{array}{l}\text { SE of } \\
\text { regression } \\
\text { on coefficient }\end{array}$ & p-value & $95 \% \mathrm{Cl}$ & \\
\hline UCPM & Total & 0.4356 & 0.1898 & 13.4770 & 0.4500 & 0.0792 & $0.0000^{*}$ & 0.2935 & 0.6066 \\
$f$ & Male & 0.5617 & 0.3155 & 12.3766 & 0.5081 & 0.0908 & $0.0000^{*}$ & 0.3270 & 0.6891 \\
& Female & 0.3657 & 0.1337 & 14.2539 & 0.4065 & 0.1246 & 0.0017 & 0.1580 & 0.6550 \\
LCPM & Total & 0.5499 & 0.3024 & 8.0234 & 0.6537 & 0.0845 & $0.0001 *$ & 0.4866 & 0.8209 \\
$¥$ & Male & 0.6868 & 0.4717 & 2.8444 & 0.8860 & 0.1137 & 0.0000 & 0.6591 & 1.1129 \\
& Female & 0.4297 & 0.1846 & 12.2872 & 0.4615 & 0.1168 & $0.0000^{*}$ & 0.2286 & 0.6944
\end{tabular}

$\mathrm{f}$ : Mesiodistal widths of maxillary canine and premolars; $¥$ : Mesiodistal widths of mandibular canine and premolars; $*$ Significant at $p<0.05$ 
coefficient higher in male subject the $r^{2}$ val ues (coefficient of determinations) ranged from 13 to $47 \%$ with power of regression model greater in male subjects.

To evaluate the applicability of Moyers probability tables, the odontometric value we obtained were statistically compared with the predicted values from M oyers table at the 50th and 75th percentile confidence levels by using Student t-test. Tables 3 and 4 shows significant difference $(p<0.05)$ at 50th and 75th percentile for both male and female in both arches. Moyers probability table underestimates tooth dimension for both male and female in both arches at 50th and 75th percentile. The new probability table of the present study on the M oyers pattern for 50th and 75th percentile confidence interval is presented in Tables 5 and 6.

The equation of Tanaka and Johnston was applied to the present samples to allow the comparison between the predicted mesiodistal width of maxillary and mandibular canine-premolar segments and the actual measured widths. Statistical comparison using t-test presented in Tables 7 and 8 showed significant differences between the predicted and measured width of maxillary and mandibular caninepremolar segments for males and females and the total samples $(p<0.05)$.

\section{DISCUSSION}

The development of two mixed dentition analysis (M oyers and Tanaka J ohnston methods), was based on data derived from a population of N orthern European descent. Therefore, the accuracy of these prediction methods may be in question when applied to population groups other than white people, because it has been well established in the literature that tooth sizes vary considerably between racial groups. D efinite racial and ethnic differences in tooth sizes have been highlighted in several population studies. ${ }^{5,8,11-13}$ The reasons for the tooth size variations in different racial groups have not been clearly elucidated, but obviously, genetic factors play a major role, and nutrition and environmental exposure during tooth development might have secondary roles. ${ }^{14}$

A gender discrepancy was seen in this study with male showing significantly greater size of maxillary caninepremolar segment. The combined mesiodistal diameter of maxillary and mandibular canine-premolar segment for both male and female in this study were relatively larger than those of measurements reported in Indian studies. ${ }^{13,15}$

Table 1 shows that mal e subjects have statistically larger mesiodistal crown width in the maxillary arch than female subjects. Difference in mesiodistal crown width between both genders in mandibular arch was not statistically significant. $V$ ery few studies in literature have attempted to investigate the error of the size prediction and its clinical significance. Othman and $\mathrm{Harradine}^{16}$ recommended a threshold of $2 \mathrm{~mm}$ in expressing a tooth size discrepancy. B ernabe et al ${ }^{17}$ how ever, chose $1.5 \mathrm{~mm}$ as a threshol d based on Proffit7 who stated that tooth size discrepancies less than this amount are rarely significant. Table 2 shows that the

Table 3: Comparison of actual measurements and predicted values of Moyers probability chart

\begin{tabular}{|c|c|c|c|c|c|}
\hline Samples & Actual vs predicted & Mean & Std. dev. & t-value & $p$-value \\
\hline Male & $\begin{array}{l}\text { UCPMf } \\
50 \% \text { max } \\
\text { UCPMf } \\
75 \% \max \end{array}$ & $\begin{array}{l}24.31 \\
21.70 \\
24.31 \\
22.24\end{array}$ & $\begin{array}{l}1.34 \\
0.78 \\
1.34 \\
0.74\end{array}$ & $\begin{array}{l}14.0672 \\
11.2895\end{array}$ & $\begin{array}{l}0.0000 * \\
0.0000 *\end{array}$ \\
\hline Female & $\begin{array}{l}\text { UCPMf } \\
50 \% \text { max } \\
\text { UCPMf } \\
75 \% \max \end{array}$ & $\begin{array}{l}23.77 \\
20.75 \\
23.77 \\
21.45\end{array}$ & $\begin{array}{l}1.73 \\
0.45 \\
1.73 \\
0.45\end{array}$ & $\begin{array}{l}14.1521 \\
10.8668\end{array}$ & $\begin{array}{l}0.0000 * \\
0.0000 *\end{array}$ \\
\hline
\end{tabular}

$* p<0.05 ; \mathrm{f}$ : Mesiodistal widths of maxillary canine and premolars

Table 4: Comparison of actual measurements, i.e. LCPM with predicted values

\begin{tabular}{lccccc}
\hline Samples & Actual vs predicted & Mean & Std. dev. & t-value & p-value \\
\hline Male & LCPM $¥$ & 23.65 & 1.91 & 9.7514 & $0.0000 *$ \\
& $50 \%$ mand & 21.29 & 0.68 & 6.4469 & $0.0000 *$ \\
Female & LCPM $¥$ & 23.65 & 1.91 & 10.4234 & $0.0000 *$ \\
& $75 \%$ mand & 22.09 & 0.68 & & $0.0000 *$ \\
& LCPM $¥$ & 23.08 & 0.65 & 6.7852 & 0.83 \\
& $50 \%$ mand & 20.78 & 1.65 & & \\
\end{tabular}

$*_{p}<0.05 ; ¥:$ Mesiodistal widths of mandibular canine and premolars 
Applicability of Two Mixed Dentition Analysis in Children of J angam Community of Belgaum City

Table 5: New Moyers probability table for prediction at 50th and 75th percentile for male

\begin{tabular}{|c|c|c|c|c|}
\hline \multirow[t]{2}{*}{ Lower incisors } & \multicolumn{2}{|c|}{ Maxillary arch } & \multicolumn{2}{|c|}{ Mandibular arch } \\
\hline & $\begin{array}{c}\text { 50th } \\
\text { percentile }\end{array}$ & $\begin{array}{c}\text { 75th } \\
\text { percentile }\end{array}$ & $\begin{array}{l}\text { 50th } \\
\text { percentile }\end{array}$ & $\begin{array}{l}\text { 75th } \\
\text { percentile }\end{array}$ \\
\hline 19.5 & 20.14 & 20.74 & 20.28 & 21.08 \\
\hline 20.5 & 20.31 & 20.90 & 20.40 & 21.20 \\
\hline 21 & 20.47 & 21.06 & 20.52 & 21.32 \\
\hline 21.5 & 20.63 & 21.21 & 20.65 & 21.45 \\
\hline 22 & 20.79 & 21.37 & 20.77 & 21.57 \\
\hline 22.5 & 20.95 & 21.52 & 20.89 & 21.69 \\
\hline 23 & 21.12 & 21.68 & 21.01 & 21.81 \\
\hline 23.5 & 21.28 & 21.84 & 21.13 & 21.93 \\
\hline 24 & 21.44 & 21.99 & 21.26 & 22.06 \\
\hline 24.5 & 21.60 & 22.95 & 21.38 & 22.18 \\
\hline 25 & 21.76 & 22.30 & 21.50 & 22.30 \\
\hline 25.5 & 21.93 & 22.46 & 21.62 & 22.42 \\
\hline
\end{tabular}

Table 6: New Moyers probability table for prediction at 50th and 75th percentile for females

\begin{tabular}{lcccc}
\hline \multirow{2}{*}{ Lower incisors } & \multicolumn{2}{c}{ Maxillary arch } & \multicolumn{2}{c}{ Mandibular arch } \\
\cline { 2 - 3 } & 50th percentile & 75th percentile & 50th percentile & 75th percentile \\
\hline 19.5 & 20.36 & 21.05 & 20.03 & 20.83 \\
20.5 & 20.40 & 21.10 & 20.24 & 20.94 \\
21 & 20.45 & 21.15 & 20.35 & 21.04 \\
21.5 & 20.49 & 21.19 & 20.45 & 21.15 \\
22 & 20.54 & 21.24 & 20.56 & 21.25 \\
22.5 & 20.59 & 21.28 & 20.66 & 21.36 \\
23 & 20.63 & 21.33 & 20.77 & 21.46 \\
23.5 & 20.68 & 21.38 & 20.87 & 21.57 \\
24 & 20.72 & 21.42 & 20.98 & 21.67 \\
24.5 & 20.77 & 21.47 & 21.08 & 21.78 \\
25 & 20.81 & 21.52 & 21.19 & 21.88 \\
25.5 & 20.86 & 21.56 & & 21.99 \\
\hline
\end{tabular}

Table 7: Comparison of actual measurements, i.e. UCPM with T and J values

\begin{tabular}{|c|c|c|c|c|c|}
\hline Samples & Actual vs predicted & Mean & Std. dev. & t-value & $\mathrm{p}$-value \\
\hline Total & $\begin{array}{l}\text { UCPMf } \\
T \text { and J max }\end{array}$ & $\begin{array}{l}24.04 \\
22.74\end{array}$ & $\begin{array}{l}1.56 \\
0.76\end{array}$ & 8.8767 & $0.0000^{*}$ \\
\hline Male & $\begin{array}{l}\text { UCPMf } \\
T \text { and J max } ¥\end{array}$ & $\begin{array}{l}24.31 \\
22.74\end{array}$ & $\begin{array}{l}1.34 \\
0.74\end{array}$ & 8.5683 & $0.0000 *$ \\
\hline Female & $\begin{array}{l}\text { UCPMf } \\
T \text { and J max } ¥\end{array}$ & $\begin{array}{l}23.77 \\
22.73\end{array}$ & $\begin{array}{l}1.73 \\
0.78\end{array}$ & 4.5943 & $0.0000 *$ \\
\hline
\end{tabular}

$* p<0.05 ;$ : Mesiodistal widths of maxillary canine and premolars; $¥:$ Tanaka and J ohnston values for maxillary arch

Table 8: Comparison of actual measurements, i.e. LCPM with T and J values

\begin{tabular}{|c|c|c|c|c|c|}
\hline Samples & Actual vs predicted & Mean & Std. dev. & t-value & $\mathrm{p}$-value \\
\hline Total & $\begin{array}{l}\text { LCPM } f \\
\mathrm{~T} \text { and J mand } ¥\end{array}$ & $\begin{array}{l}23.37 \\
22.22\end{array}$ & $\begin{array}{l}1.80 \\
0.75\end{array}$ & 6.9566 & $0.0000 *$ \\
\hline Male & $\begin{array}{l}\text { LCPM } f \\
\mathrm{~T} \text { and J mand } ¥\end{array}$ & $\begin{array}{l}23.65 \\
22.21\end{array}$ & $\begin{array}{l}1.91 \\
0.72\end{array}$ & 5.9050 & $0.0000 *$ \\
\hline Female & $\begin{array}{l}\text { LCPM } f \\
T \text { and J mand } ¥\end{array}$ & $\begin{array}{l}23.08 \\
22.23\end{array}$ & $\begin{array}{l}1.65 \\
0.78\end{array}$ & 3.9101 & $0.0001^{*}$ \\
\hline
\end{tabular}

${ }^{*} p<0.05$; $f$ : Mesiodistal widths of mandibular canine and premolars; $¥$ : Tanaka and J ohnston values for mandibular arch 
mesiodistal crown widths of all tooth groups measured in this study were larger in males than in females, as cited in other studies. Standard errors of the mean of this study are relatively low, indicating a reduced variance about the mean for the predictions.

The accurate width of an unerupted tooth is important for correct diagnosis of case, neither over estimation nor under estimation of width should be done for accurate treatment plan. This study reveals that $M$ oyers chart at 50 th and 75th percentile confidence level underestimates the tooth dimension for both male and female in both the arches.

Tables 3 and 4 show that there is statistical significant difference in tooth dimension between the actual and predicted value at the 50 th and 75 th percentile of the $M$ oyers probability tables for males and females in both the arches. Accurate treatment planning in management of mixed dentition cases is of great importance but if predicted values of the width of canine and premolars itself is wrong, the whole treatment may be a failure. A difference of $\pm 2 \mathrm{~mm}$ per arch between the predicted width and actual width is clinically significant as it affects extraction decisions in patients with moderate crowding in mixed dentition cases.

A I-K hadra found that the recommended 75th percentile confidence level of the Moyers probability tables overestimated the sizes of canines and premolars of a Saudi A rab population. ${ }^{18}$

A $n$ investigation was conducted in the Department of Orthodontics, College of Dental Surgery, M anipal to evaluate the applicability of M oyers mixed dentition space analysis for the south Indian population. The samples were taken from 50 male and 50 female subjects. Teeth were measured using a fine gauge calibrated to $0.1 \mathrm{~mm}$. Results showed that 35 percentile is more accurate than 75th percentile level of probability, as suggested by M oyers. ${ }^{19}$

The findings of the present study were similar to that of studies conducted by Philip et al ${ }^{15}$ and Priya and $\mathrm{M}$ unshi. ${ }^{13}$ It can be generally stated that the Moyers table tend to underestimate the mesiodistal canine premolar width of this racial group at the recommended 50th and 75th percentile.

B uwembo and Luboga ${ }^{20}$ conducted a meta-analysis on the applicability of M oyer's method in different ethnic groups and concluded that it cannot be universally applied to different populations and it is safer to develop prediction tables for specific populations.

Present study also showed that Tanaka and Johnston's method of prediction underestimates the tooth dimension of both maxillary and mandibular buccal segments compared with actual measurement of study cast. This finding was in contrast to that of A sian A mericans, ${ }^{5}$ Senegalese, ${ }^{21}$ black South A fricans, ${ }^{22}$ J ordanians ${ }^{23}$ and Saudi A rabians ${ }^{18}$ who concluded that Tanaka and J ohnston method of prediction over estimates tooth sizes of their population.

Field ${ }^{24}$ stated that the accuracy of the M oyers mixed dentition space analysis method is fairly good when applied exclusively to white patients. Our results confirmed that the M oyers probability and Tanaka and J ohnston methods underestimate tooth sizes of $\mathrm{J}$ angam population of B el gaum city.

Pedodontists and orthodontist might be treating children of various racial and ethnic mixes, and will benefit by using mixed dentition prediction aids developed for specific population groups, such as those proposed in this study for J angam population of Indian origin.

\section{CONCLUSION}

1. Moyer prediction table and Tanaka and Johnston prediction method were not accurate when applied to our sample. There are limitations in their application to Jangam population.

2. A gender discrepancy was seen in this study with male showing significantly greater size of maxillary caninepremolar segment.

3. The M oyers probability tables and Tanaka and J ohnston prediction method were found to significantly underestimate canine and premolar mesiodistal width of J angam population.

4. We recommend that the new probability tables proposed in this study should be used for mixed dentition space analysis in Jangam population of Indian origin. However, the accuracy of the proposed prediction aids should be further tested in other ethnic groups of India.

\section{REFERENCES}

1. Cunat JJ. Tooth size prediction in the mixed dentition. NYS Dent J 1982;48:88-91.

2. Proffit WR, Fields HW. Contemporary orthodontics (3rd ed). St Louis, M o: M osby; 2000;167-70.

3. Huckaba GW . A rch size analysis and tooth size prediction. D ent Clin N orth A m 1964;11:431-40.

4. Smith HP, K ing DL, V alencia R. A comparison of three methods of mixed-dentition analyses. J Pedod 1979;3:291-302.

5. Lee-Chan S, Jacobson BN, Chwa K, Jacobson JS. M ixed D entition for A sian-A mericans. A m J Orthod Dentofac Orthop 1998;113:293-99.

6. Bishara SE, Jakobsen JR. Comparison of two non-radiographic methods of predicting permanent tooth size in the mixed dentition. A m J Orthod Dentofac Orthop 1998;113:573-76.

7. Richardson ER, M al hotra SK. M esiodistal crown dimension of the permanent dentition of A merican Negroes. A $m$ J Orthod 1975;68:157-64.

8. Bishara SE, J akobsen JR, A bdallah EM, Fernandez Garcia A. Comparisons of mesiodistal and buccolingual crown dimensions of the permanent teeth in three populations from Egypt, M exico and the United States. A m J Orthod Dentofacial Orthop 1989;96:416-22. 
9. M oorrees CFA, Reed R B. Correlations among crown diameters of human teeth. A rch Oral Biol 1964;9:685-97.

10. Doris J M, Bernard BW, K uftinec M M, Stom D. A biometric study of tooth size and dental crowding. Am J Orthod 1981;79:326-35.

11. Lavelle CLB. M axillary and mandibular tooth size in different racial groups and in different occlusal categories. A $m$ J Orthod 1972;61:29-37.

12. J aroontham J, Godfrey K. M ixed dentition space analysis in a Thai population. Eur J Orthod 2000;22:127-34.

13. Priya S, M unshi AK . Formulation of a prediction chart for mixed dentition analysis. J Indian Soc Pedod Prev Dent 1994;12:7-11.

14. Garn SM. Genetics of dental development. The biology of occlusal devel opment. M onograph 7, Craniofacial growth series. Ann A rbor: Center for Human Growth and Development; University of M ichigan; 1977.

15. Philip NI, Prabhakar M, A rora A, Chopra S. A pplicability of the $M$ oyers mixed dentition probability tables and new prediction aids for a contemporary population in India. A m J Orthod Dentofacial Orthop 2010;138:339-45.

16. Othman S, Harradine N. Tooth size discrepancies in an orthodontic population. A ngle Orthod 2007;77:668-74.

17. Bernabe' $E, M$ ajor PW, Flores-M ir C. Tooth-width ratio discrepancies in a sample of Peruvian adolescents. A m J Orthod Dentofacial Orthop 2004;125:361-65.

18. AI-K hadra B H. Prediction of the sizes of unerupted canines and premolars in a Saudi A rab population. A m J Orthod Dentofacial Orthop 1993;104:369-72.

19. Rani M S, Goel. Evaluation of M oyers mixed dentition analysis for south Indian population. J Indian Dent A ssoc 1989;60: 253-55.

20. Buwembo W, Luboga S. M oyer's method of mixed dentition analysis: A meta-analysis. Afr Health Sci 2004;4(1):63-66.
21. Diagne F, Diop-Ba K, N gom PI, M bow K. M ixed dentition analysis in a Senegalese population: Elaboration of prediction tables. A m J Orthod Dentofacial Orthop 2003;124(2):178-83.

22. Schirmer UR, W iltshire WA . O rthodontic probability tables for black patients of $A$ frican descent: $M$ ixed dentition analysis. A m J Orthod Dentofacial Orthop 1997;112(5):545-51.

23. Al-Bitara ZB, Al-O marib IK, Sonbol HN, Al-A hmadd HT, Hamdan A M. Mixed dentition analysis in a Jordanian population. A ngle Orthod 2008;78:670-75.

24. Fields HW. Treatment of moderate nonskeletal problems in preadolescent children. In: Proffit WR, Fields HW (Eds). Contemporary orthodontics (3rd ed). St Louis: CV M osby; 2000:417-22.

\section{ABOUT THE AUTHORS}

\section{Santosh M Sholapurmath}

A ssociate Professor, D epartment of Pediatric and Preventive D entistry $M$ aratha $M$ andals NGH Institute of Dental Sciences and Research Centre, B elgaum, Karnataka, India

\section{Deepa B Benni (Corresponding Author)}

Senior L ecturer, D epartment of Pediatric and Preventive Dentistry $M$ aratha $M$ andals N GH Institute of D ental Sciences and Research Centre, B elgaum, K arnataka, India, Phone: 09480604088 e-mail: deepbenni@yahoo.co.in

\section{Praveen Mandroli}

Professor and Head, D epartment of Pediatric and Preventive Dentistry $M$ aratha $M$ andals NGH Institute of Dental Sciences and Research Centre, B elgaum, Karnataka, India 